SUPPORTING INFORMATION

\title{
Dechlorinating Chloroacetanilide Herbicides by Dithionite-Treated Aquifer Sediment and Surface Soil
}

\author{
HARDILJEET K. BOPARAI, PATRICK J. SHEA,* STEVE D. COMFORT \\ AND DANIEL D. SNOW \\ School of Natural Resources, University of Nebraska-Lincoln, Lincoln, NE 68583-0915
}

Environmental Science and Technology

3 pages, 3 figures 


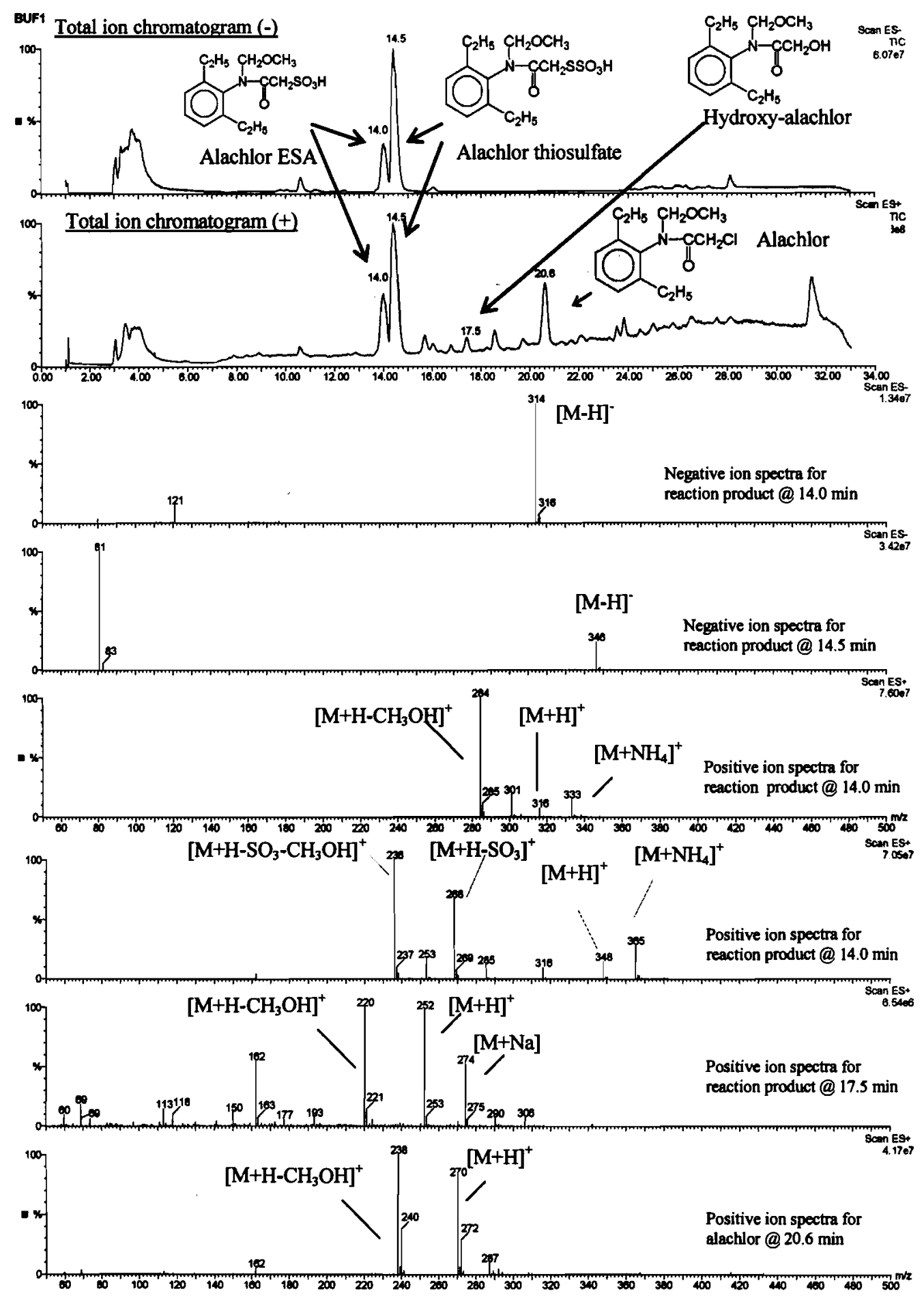

FIGURE S1. Negative and positive mode total ion chromatograms and spectra for products of dithionite-treated alachlor in citrate-bicarbonate buffer $(20 \mathrm{mM}$ dithionite, pH 8.5). 


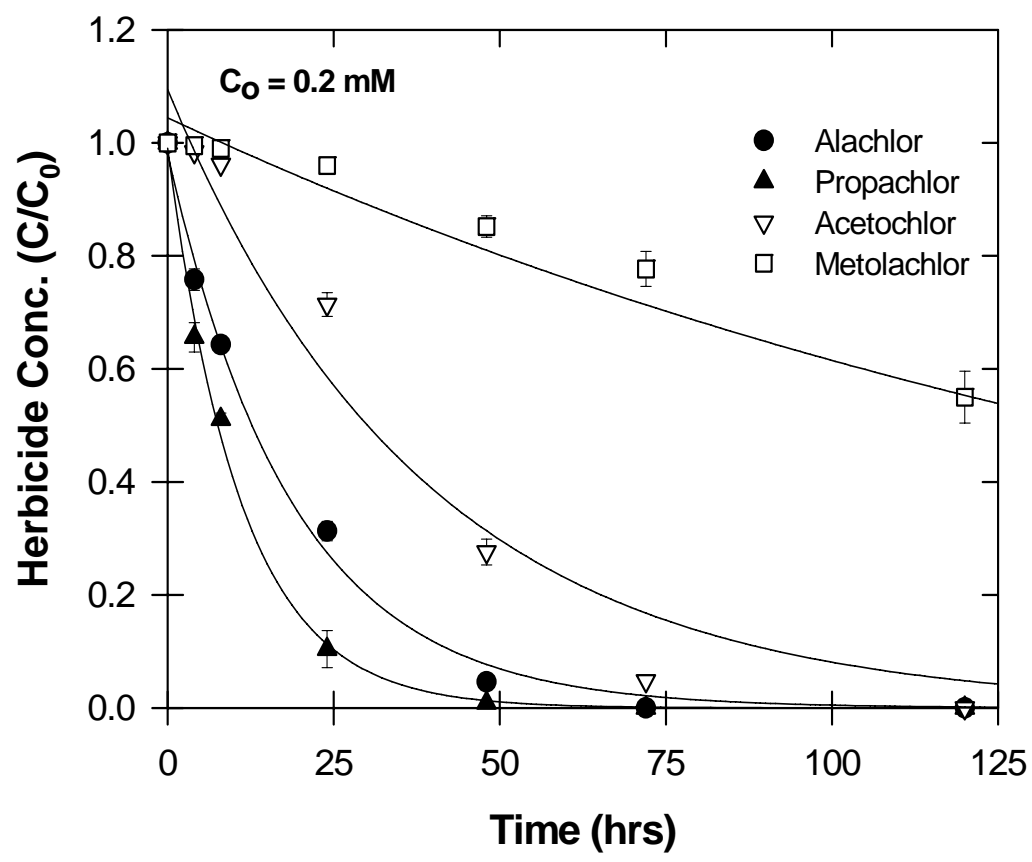

FIGURE S2. Transformation of chloroacetanilide herbicides in citrate-bicarbonate buffered (pH 8.5), $20 \mathrm{mM}$ dithionite solutions. Bars on symbols represent standard deviations; where absent, bars fall within symbols. 


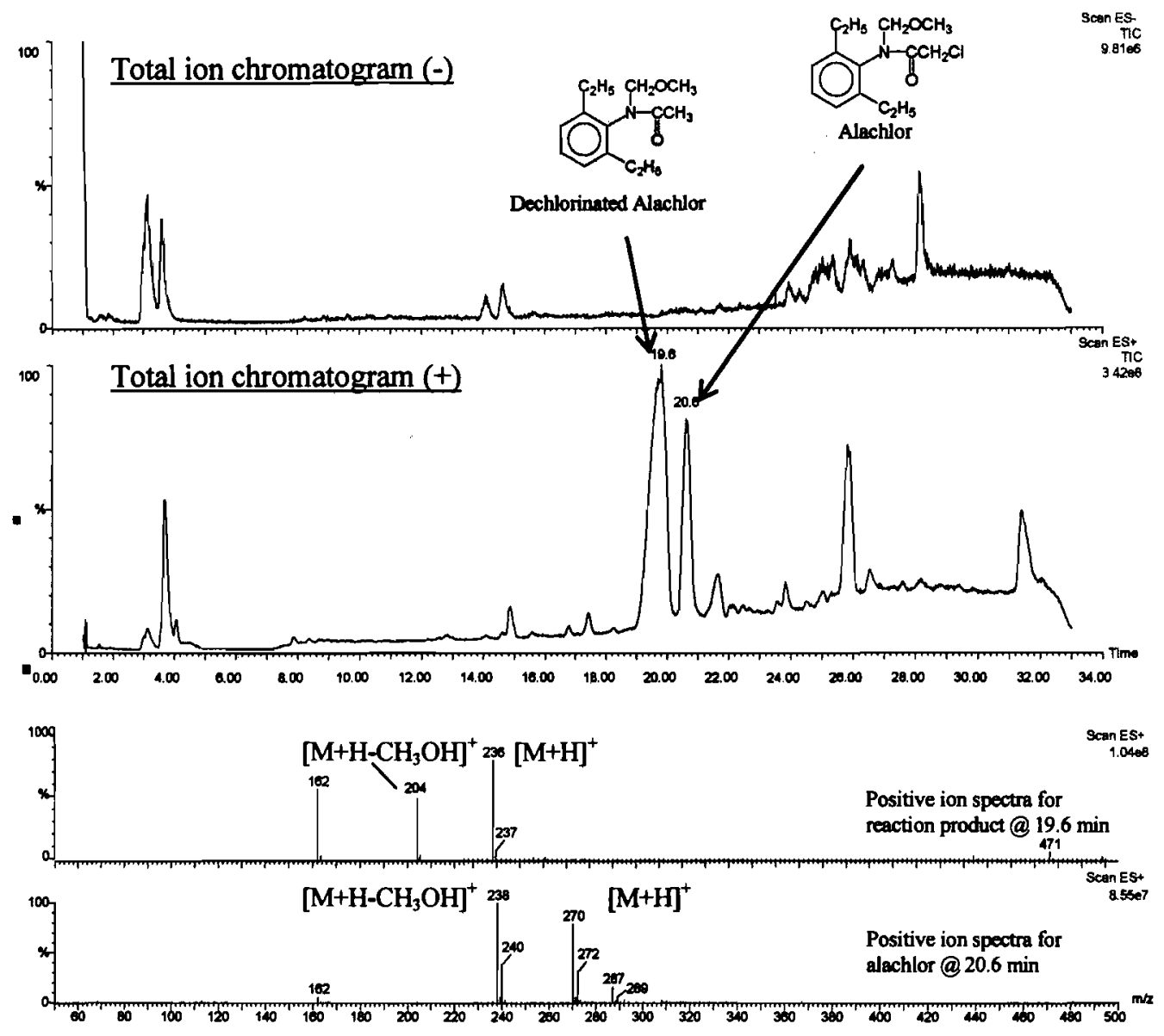

FIGURE S3. Negative and positive mode total ion chromatograms and spectra showing the dechlorinated alachlor product of transformation by dithionite-reduced Pantex sediment in potassium carbonate buffer. Small peaks corresponding to alachlor thiosulfate, alachlor ESA, and hydroxyalachlor are not labeled (shown in Figure S1). 